\title{
Opposite Effects of Basolateral Amygdala Inactivation on Context-Induced Relapse to Cocaine Seeking after Extinction versus Punishment
}

\author{
Yann Pelloux, Angelica Minier-Toribio, Jennifer K. Hoots, ${ }^{\top}$ Jennifer M. Bossert, ${ }^{*}$ and $\odot$ Yavin Shaham ${ }^{*}$ \\ Behavioral Neuroscience Branch, Intramural Research Program, NIDA, Baltimore, Maryland 21224
}

Studies using the renewal procedure showed that basolateral amygdala (BLA) inactivation inhibits context-induced relapse to cocaineseeking after extinction. Here, we determined whether BLA inactivation would also inhibit context-induced relapse after drug-reinforced responding is suppressed by punishment, an animal model of human relapse after self-imposed abstinence due to adverse consequences of drug use. We also determined the effect of central amygdala (CeA) inactivation on context-induced relapse.

We trained rats to self-administer cocaine for $12 \mathrm{~d}(6 \mathrm{~h} / \mathrm{d})$ in Context A and then exposed them to either extinction or punishment training for $8 \mathrm{~d}$ in Context B. During punishment, $50 \%$ of cocaine-reinforced lever-presses produced an aversive footshock of increasing intensity $(0.1-0.5$ or $0.7 \mathrm{~mA})$. We then tested the rats for relapse to cocaine seeking in the absence of cocaine or shock in Contexts A and $\mathrm{B}$ after BLA or CeA injections of vehicle or GABA agonists (muscimol-baclofen). We then retrained the rats for cocaine self-administration in Context A, repunished or re-extinguished lever pressing in Context $B$, and retested for relapse after BLA or CeA inactivation.

BLA or CeA inactivation decreased context-induced relapse in Context A after extinction in Context B. BLA, but not CeA, inactivation increased context-induced relapse in Context A after punishment in Context B. BLA or CeA inactivation provoked relapse in Context B after punishment but not extinction. Results demonstrate that amygdala's role in relapse depends on the method used to achieve abstinence and highlights the importance of studying relapse under abstinence conditions that more closely mimic the human condition.

Key words: amygdala; cocaine; extinction; punishment; reinstatement; relapse

Significance Statement

Relapse to drug use during abstinence is often provoked by re-exposure to the drug self-administration environment or context. Studies using the established extinction-reinstatement rodent model of drug relapse have shown that inactivation of the basolateral amygdala inhibits context-induced drug relapse after extinction of the drug-reinforced responding. Here, we determined whether basolateral amygdala inactivation would also inhibit relapse after drug-reinforced responding is suppressed by punishment, a model of human relapse after self-imposed abstinence. Unexpectedly, we found that basolateral amygdala inactivation had opposite effects on relapse provoked by re-exposure to the drug self-administration environment after extinction versus punishment. Our results demonstrate that depending on the historical conditions that lead to abstinence, amygdala activity can either promote or inhibit relapse.

\section{Introduction}

In humans, environmental contexts previously associated with drug use often provoke relapse during abstinence (Wikler, 1973;

\footnotetext{
Received Aug. 25, 2017; revised 0ct. 20, 2017; accepted 0ct. 26, 2017.

Author contributions: Y.S., Y.P., and J.M.B. designed research; Y.S., Y.P., J.M.B., A.M.-T., and J.K.H. performed research; Y.S., Y.P., J.M.B., A.M.-T., and J.K.H. analyzed data; Y.S., Y.P., J.M.B., A.M.-T., and J.K.H. wrote the paper.

This work was supported by the Intramural Research Program of NIDA (Y.S.), and a fellowship from the NIDAINSERM program (Y.P.).

The authors declare no competing financial interests.

*J.M.B. and Y.S. contributed equally as co-senior authors.

Correspondence should be addressed to either Dr. Yann Pelloux or Yavin Shaham, Behavioral Neuroscience Branch, Intramural Research Program, NIDA, 251 Bayview Boulevard, Suite 200, Baltimore, MD 21224, E-mail: yann.pelloux@nih.gov or yavin.shaham@nih.gov.
}

O'Brien et al., 1992). In rats, studies using the ABA renewal procedure (Bouton and Bolles, 1979) demonstrated that exposure to the drug self-administration context (Context A) after extinction of the drug-reinforced responding in a different context (Context B) reinstates drug seeking (Crombag et al., 2008; Lasseter et al., 2010; Khoo et al., 2017). However, from a clinical perspective, a limitation of the classical extinction-reinstatement model is the use of operant extinction to achieve abstinence; this is because human abstinence rarely involves overt extinction of drug seeking (Marlatt, 2002; Epstein et al., 2006). Instead, abstinence is 
often self-imposed because of adverse consequences of drug use (Waldorf et al., 1991; Vanderschuren et al., 2017).

To address the lack of homology between the human condition and the animal model, we recently developed a relapse model in which drug self-administration is suppressed by adverse consequences (punishment; Marchant et al., 2013b). The model is a modified ABA renewal procedure where abstinence is achieved in Context B by probabilistic punishment (response-contingent footshocks). Using this model, we demonstrated context-induced relapse to alcohol and cocaine seeking when rats were tested in Context A after punishment-imposed abstinence in Context B (Marchant et al., 2014, 2016; Pelloux et al., 2017).

The main question that inspired our studies on contextinduced relapse after punishment-imposed abstinence (Marchant et al., 2013b) is whether similar or different mechanisms mediate context-induced relapse after extinction-induced suppression of drug seeking in the absence of the drug versus punishmentinduced suppression of drug seeking in the presence of the drug. This question is important because it has been argued that the use of operant extinction limits the validity of the extinctionreinstatement procedure as a model of human drug relapse (Marlatt, 2002; Katz and Higgins, 2003). To date, the available data suggest an overlap between brain regions and circuits controlling context-induced reinstatement after extinction and punishment. Specifically, context-induced relapse to drug seeking after either extinction or punishment is associated with activation of projections from lateral hypothalamus and ventral subiculum to nucleus accumbens shell, and inactivation of these three brain regions inhibits both forms of relapse (Marchant et al., 2015; Khoo et al., 2017). However, the tentative conclusion that context-induced relapse after extinction or punishment involves similar circuit mechanisms is based on historical comparisons from independent studies conducted under different experimental conditions that used different drugs (alcohol, cocaine, heroin).

Based on these considerations, we more formally explored our initial question on whether similar or different mechanisms control context-induced relapse to drug seeking after extinction versus punishment by studying the role of the basolateral amygdala (BLA) in cocaine-experienced rats. We chose the BLA because previous studies using the activity marker Fos showed that this brain region is activated during tests for context-induced relapse after either extinction (Hamlin et al., 2008) or punishment (Marchant et al., 2016; Pelloux et al., 2017). Additionally, BLA inactivation inhibits context-induced reinstatement of cocaine and alcohol seeking (Fuchs et al., 2005; Chaudhri et al., 2013). We also chose the BLA because of its role in punishment-controlled responding (Pelloux et al., 2013; Jean-Richard-Dit-Bressel and McNally, 2015; Orsini et al., 2015a,b; Piantadosi et al., 2017). Finally, we determined the role of the central amygdala nucleus $(\mathrm{CeA})$ in context-induced relapse after either extinction or punishment, because its role in context-induced relapse after extinction or punishment is unknown. However, previous studies demonstrated a role of $\mathrm{CeA}$ in punishment-induced suppression of cocaine seeking (Xue et al., 2012), cue-induced reinstatement of cocaine seeking (Kruzich and See, 2001; Alleweireldt et al., 2006), and incubation of drug craving (the time-dependent increases in drug seeking after withdrawal) across drug classes ( $\mathrm{Lu}$ et al., 2005; Li et al., 2015; Funk et al., 2016). We used a classical muscimol-baclofen $\left(\mathrm{GABA}_{\mathrm{A}}+\mathrm{GABA}_{\mathrm{B}}\right.$ agonists) reversible inactivation procedure (McFarland and Kalivas, 2001) to demonstrate that amygdala inhibition has opposite effects on context-induced relapse after extinction versus punishment.

\section{Materials and Methods}

\section{Subjects}

We used male Sprague-Dawley rats (Charles River Laboratories; total $N=88$ ), weighing $250-350 \mathrm{~g}$ before surgery. We maintained the rats under a reverse $12 \mathrm{~h} \mathrm{light/dark} \mathrm{cycle} \mathrm{(lights} \mathrm{off} \mathrm{at} \mathrm{8:00} \mathrm{A.M.)} \mathrm{with} \mathrm{food}$ and water available ad libitum. We housed two rats per cage before surgery and then individually after surgery. We performed all experiments in accordance with the National Institutes of Health Guide for the Care and Use of Laboratory Animals (Ed. 8), under protocols approved by the Animal Care and Use Committee. We excluded 33 rats, due to either failure of catheter patency $(n=17)$ or misplaced cannulas $(n=16)$.

\section{Intravenous and intracranial surgeries}

We anesthetized the rats with isoflurane (5\% induction; $2-3 \%$ maintenance). We attached silastic catheters to a modified 22 gauge cannula cemented to polypropylene mesh (Small Parts), inserted the catheter into the jugular vein, and fixed the mesh to the mid-scapular region as described previously (Bossert et al., 2016; Adhikary et al., 2017; Caprioli et al., 2017; Venniro et al., 2017a). We then implanted guide cannulas (23 gauge; Plastics One) $1 \mathrm{~mm}$ above the target sites. Based on pilot and previous studies (Li et al., 2015; Venniro et al., 2017b), we set the nose bar at $-3.3 \mathrm{~mm}$ and used the following coordinates from bregma: BLA: anterior-posterior $(\mathrm{AP})-2.5 \mathrm{~mm}$, mediolateral $(\mathrm{ML}) \pm 5.3 \mathrm{~mm}$, dorsoventral (DV) $-7.8 \mathrm{~mm}$ for the first run, and AP $-2.5 \mathrm{~mm}, \mathrm{ML} \pm 5.0$ $\mathrm{mm}, \mathrm{DV}-8.2 \mathrm{~mm}$ for subsequent runs where we adjusted the coordinates because of misplaced cannulas dorsal to BLA in the first run (see the next section); the CeA coordinates were as follows: $\mathrm{AP}-2.3 \mathrm{~mm}, \mathrm{ML}$, \pm 4.0 , DV $-8.0 \mathrm{~mm}$ (Paxinos and Watson, 2008). We anchored the cannulas to the skull with jeweler's screws and dental cement. After surgery and on the following day, we injected the rats with ketoprofen (2.5 $\mathrm{mg} / \mathrm{kg}$, s.c.; Butler Schein) to relieve pain and decrease inflammation. We allowed the rats 5-7 d to recover before cocaine self-administration training. During the recovery and training phases, we flushed the catheters every day with gentamicin $(4.25 \mathrm{mg} / \mathrm{ml}$, APP Pharmaceuticals) dissolved in sterile saline.

\section{Intracranial injections}

We connected the syringe pump (Harvard Apparatus) to $10 \mu$ Hamilton syringes and attached the Hamilton syringes to 30 gauge injectors via polyethylene-50 tubing; the injectors extended $1 \mathrm{~mm}$ below the tips of the guide cannulas. We dissolved muscimol-baclofen (Tocris Bioscience; $50+50 \mathrm{ng}$ in $0.5 \mu \mathrm{l}$ per side) in sterile saline. We made all intracranial injections over $1 \mathrm{~min}$ and left the injectors in place for an additional minute to allow drug diffusion. After the final tests, we anesthetized the rats, removed their brains, and stored the brains in $10 \%$ formalin. We sectioned brains at $50 \mu \mathrm{m}$ using a Leica Microsystems cryostat and stained sections with cresyl violet to verify the placement of the cannulas under a light microscope. Based on the histological verification, we excluded 10 rats from the first run (where we studied the effect of BLA inactivation on relapse after punishment) and 6 rats from the subsequent runs ( 2 additional rats from the BLA inactivation-punishment group, 1 rat from the BLA inactivation-extinction group, and 3 rats from the CeA inactivation-punishment group).

\section{Apparatus}

We trained and tested the rats in standard Med Associates self-administration chambers located inside sound-attenuating cabinets. Each chamber had two levers located $7.5-8.0 \mathrm{~cm}$ above the grid floor on opposing walls. Lever presses on the active retractable lever activated the infusion pump, whereas lever presses on the inactive nonretractable lever had no programmed consequences. The grid floors were connected to Med Associates shockers. We modified the self-administration chambers to two contexts (A and B) that differed from each other in their auditory, visual, and tactile features, using procedures like those described in our previous studies (Bossert et al., 2004; Marchant et al., 2013b; Adhikary et al., 2017; Pelloux et al., 2017). In one context, we kept the doors of the sound-attenuating cabinet open, a white house light provided illumination, the fan was turned off, the floor consisted of 26 stainless-steel rods (3.2 mm diameter) spaced $11 \mathrm{~mm}$ apart, and there was an empty feeder in 
the chamber. In the other context, the cabinet doors remained closed during the session, illumination was provided by a red house light, the fan was turned on, the floor consisted of 19 stainless-steel rods $(4.8 \mathrm{~mm}$ diameter) spaced $16 \mathrm{~mm}$ apart, and there was no feeder in the chamber. The contexts are referred to as A and B, where A is the cocaine selfadministration training context and B is the punishment or extinction context. We counterbalanced the physical environments of Contexts A and $\mathrm{B}$.

\section{Procedures}

The experimental parameters for the self-administration, punishment, and relapse phases were based on those used in our previous studies on context-induced relapse to drug seeking after punishment-imposed abstinence (Marchant et al., 2013b, 2014, 2016; Marchant and Kaganovsky, 2015; Pelloux et al., 2017). The experimental parameters for the extinction phases were based on our previous studies on context-induced reinstatement of heroin seeking after extinction (Bossert et al., 2004, 2016). For each amygdala subregion (BLA, CeA), we compared the effect of muscimol-baclofen inactivation on context-induced relapse after punishment- or extinction-imposed abstinence, using a counterbalanced within-subject design. We tested the effect of vehicle and muscimol-baclofen injections on non-reinforced lever presses in Contexts A and B in two sets of relapse tests (see next section). This experimental design is based on our previous study (Pelloux et al., 2017) and ongoing studies in the laboratory where we do not observe an order effect of the repeated testing procedure.

The experiments consisted of six phases: (1) self-administration training (Context A; $12 \mathrm{~d}$ ), (2) punishment or extinction training (Context B; $8 \mathrm{~d}$ ), (3) tests for context-induced relapse of cocaine seeking (Contexts A and B; 2 d), (4) self-administration retraining (Context A; 4 d), (5) punishment or extinction retraining (Context $B ; 8 \mathrm{~d}$ ), and (6) retests for context-induced relapse of cocaine seeking (Contexts A and B; $2 \mathrm{~d}$ ). The timeline is shown in Figure $1 A$. This repeated testing procedure is based on our recent study (Pelloux et al., 2017).

\section{Drugs}

For the self-administration and punishment phases, the rats self-administered cocaine- $\mathrm{HCl}$ (dose: $0.75 \mathrm{mg} / \mathrm{kg} /$ infusion). We obtained cocaine hydrochloride (dissolved in sterile saline $0.9 \%$ ) from NIDA pharmacy. For the relapse tests, we used a mixture of the $\mathrm{GABA}_{\mathrm{A}}$ and $\mathrm{GABA}_{\mathrm{B}}$ (respectively) agonists, muscimol-baclofen (Tocris Bioscience; $50+50 \mathrm{ng}$ dissolved in $0.5 \mu \mathrm{l}$ of sterile saline per side). We used these doses of muscimol and baclofen based on previous studies (Stopper and Floresco, 2014; Venniro et al., 2017b).

\section{Phase 1: cocaine self-administration in Context $A$}

We trained the rats to self-administer cocaine for $6 \mathrm{~h} / \mathrm{d}$ for $12 \mathrm{~d}$. As in our recent study (Pelloux et al., 2017), we used an extended daily cocaine self-administration training procedure because this procedure mimics human drug use characterized by escalation of drug intake over time (Ahmed and Koob, 1998). The sessions began with the extension of the active lever and the illumination of the house light, which remained on for the duration of the $6 \mathrm{~h}$ session. Active lever presses led to the delivery of a cocaine infusion $(0.75 \mathrm{mg} / \mathrm{kg} /$ infusion; $0.10 \mathrm{ml} /$ infusion over $5 \mathrm{~s})$ and a compound tone-light cue. During the first six sessions, we trained the rats using a fixed-ratio-1 (FR-1) 20 s timeout reinforcement schedule, and during the last six sessions, we trained the rats using a variableinterval $30 \mathrm{~s}$ (VI-30) reinforcement schedule in which cocaine delivery after an active lever press was available at random intervals (range: 1-59 s) after the preceding cocaine delivery. We recorded lever presses during the timeout intervals, but the lever presses during this time period had no consequences. We previously used the VI-30 reinforcement schedule in our alcohol and cocaine studies (Marchant et al., 2013b, 2014, 2016; Marchant and Kaganovsky, 2015; Pelloux et al., 2017).

\section{Phase 2: punishment or extinction in Context B}

During this phase, all rats were in Context $\mathrm{B}$ for $6 \mathrm{~h} / \mathrm{d}$ sessions for $8 \mathrm{~d}$. For the Punishment group, $50 \%$ of the reinforced lever presses, which occurred after the VI-30 response requirement was met, delivered a $0.5 \mathrm{~s}$ footshock through the grid floor, in addition to the tone-light cue and cocaine infusion. The first session began without any shock $(0.0 \mathrm{~mA})$, and thereafter we began with $0.1 \mathrm{~mA}$ shock and increased the intensity by $0.1 \mathrm{~mA}$ every day until the last day $(0.5$ or $0.7 \mathrm{~mA})$. For the extinction group, responses on the previously active lever led to presentation of the tone-light cue but no shock or cocaine was delivered.

\section{Phase 3: relapse Test 1}

We tested all rats for cocaine seeking (operationally defined as active lever presses under extinction conditions) in both Contexts A and B in $1 \mathrm{~h}$ extinction sessions over 2 consecutive days with the order of testing counterbalanced for both groups. We performed the first test $24 \mathrm{~h}$ after the final Context B training session and separated the tests by $24 \mathrm{~h}$. We assigned the rats to either the vehicle condition or the muscimol-baclofen condition. On the first day, we injected the rats with either vehicle or muscimol-baclofen and tested them in either Context A or Context B. On the second day, the rats injected with vehicle on the first day were injected again with vehicle and tested in the other context. Similarly, the rats injected with muscimol-baclofen on the first day were injected again with muscimol-baclofen and tested in the other context. The duration of the tests was $1 \mathrm{~h}$ to minimize carryover effect of extinction learning, which may decrease drug seeking during the subsequent relapse test (retest or Test 2) after retraining and repunishment or re-extinction (see next section).

\section{Phases 4-6: self-administration retraining, punishment or extinction retraining, and retest (Test 2 )}

We retrained the rats for $6 \mathrm{~h} / \mathrm{d}$ for $4 \mathrm{~d}$ under a VI-30 schedule of reinforcement in Context A, as described above in Phase 1. We performed punishment or extinction retraining in Context $\mathrm{B}$ for $8 \mathrm{~d}$, as described in Phase 2. Then, we retested the rats as described in Phase 3 (relapse Test 1). During retest (Test 2), the rats injected with vehicle during Test 1 were injected with muscimol-baclofen and the rats injected with muscimolbaclofen during Test 1 were injected with vehicle. As in Test 1 , we counterbalanced the order of testing in Contexts A and B for both groups of rats.

\section{Experimental design and statistical analysis}

Experiment 1: effect of BLA inactivation on context-induced relapse of cocaine seeking after punishment or extinction. We used a $2 \times 2 \times 2$ mixed factorial design with the between-subjects factor of Abstinence condition (punishment, extinction) and the within-subjects factors of Context $(\mathrm{A}, \mathrm{B})$ and muscimol-baclofen dose $(0,50+50)$. We trained the rats to self-administer cocaine in Context $A$ and subsequently punished or extinguished the cocaine-reinforced responding in Context $\mathrm{B}$. We gave all rats eight punishment or extinction sessions before each set of relapse tests for context-induced relapse (initial test or Test 1 and retest or Test $2)$. For the Punishment group $(n=11)$, we increased the shock intensity from 0.0 to $0.7 \mathrm{~mA}$ in $0.1 \mathrm{~mA}$ increments per session. For the Extinction group $(n=12)$, responses on the previously active lever led to presentations of the tone-light cue but no cocaine was delivered. We tested for context-induced relapse after BLA vehicle or muscimol-baclofen intracranial injections in 60 min sessions in both Contexts A and B under extinction conditions over consecutive days (counterbalanced order).

Experiment 2: effect of CeA inactivation on context-induced relapse of cocaine seeking after punishment or extinction. We used a $2 \times 2 \times 2$ mixed factorial design with the between-subjects factor of Abstinence condition (punishment, extinction) and the within-subjects factors of Context $(\mathrm{A}, \mathrm{B})$ and muscimol-baclofen dose $(0,50+50)$. We trained rats to self-administer cocaine in Context A and subsequently punished or extinguished the cocaine-reinforced responding in Context $\mathrm{B}$. We gave all rats eight punishment or extinction sessions before each set of relapse tests for context-induced relapse (initial test or Test 1 and retest or Test $2)$. For the Punishment group $(n=14)$, we increased the shock intensity daily from 0.0 to $0.5 \mathrm{~mA}$ in $0.1 \mathrm{~mA}$ increments. On punishment days 6 and 7 , we kept the shock intensity at $0.5 \mathrm{~mA}$. For the Extinction group $(n=16)$, responses on the previously active lever led to presentations of the tone-light cue but no cocaine was delivered. We tested for contextinduced relapse after CeA vehicle or muscimol-baclofen intracranial injections in 60 min sessions in both Contexts $\mathrm{A}$ and $\mathrm{B}$ under extinction conditions over consecutive days. 


\section{Statistical analysis}

Using the statistical program SPSS, we analyzed the data separately for the different phases of training, punishment, and relapse tests. We used mixed ANOVAs (see Results for the description of the between- and within-subjects factors) and followed up on significant main effects and interaction effects $(p<0.05)$ with post hoc tests (Fisher PLSD). Because our multifactorial ANOVAs yielded multiple main and interaction effects, we only report significant effects that are critical for data interpretation. Additionally, for clarity, we primarily indicate post hoc analyses by asterisks in the figures. We excluded two rats ( 1 from Experiment 1 and 1 from Experiment 2), because in one or more of the relapse tests, their values were over $3 \mathrm{SD}$ above their group mean (our statistical exclusion criterion). Finally, the different experimental manipulations had no effect on the number of inactive lever presses, which was very low during testing (mean of 2 or less presses per $60 \mathrm{~min}$ ). Therefore, we do not present the inactive lever data in the Results section or the figures.

\section{Results}

\section{Self-administration, punishment, and extinction phases}

As in our previous study (Pelloux et al., 2017), the rats in the Punishment and Extinction groups demonstrated reliable cocaine self-administration in Context A under the FR-1 and VI-30 reinforcement schedules (Figs. 1,2). During the cocaine selfadministration retraining phase in Context $\mathrm{A}$, the rats in the two groups rapidly reacquired cocaine self-administration under the VI-30 reinforcement schedule (Figs. 1, 2). During the punishment and repunishment phases in Context B, the rats in the Punishment group decreased the number of cocaine infusions and active lever presses with increasing shock intensity over days (Figs. 1, 2). Similarly, during the extinction and re-extinction phases in Context B, the rats in the Extinction group decreased the number of active lever presses over days (Figs. 1, 2).

\section{Relapse tests}

Effect of BLA inactivation on context-induced relapse after punishment versus extinction (Experiment 1)

We observed selective context-induced relapse to cocaine seeking in Context A after suppression of responding in Context B in both the Punishment and Extinction groups (Fig. $1 \mathrm{~J}, \mathrm{~K}$; vehicle conditions), confirming previous reports on context-induced relapse to cocaine seeking after extinction or punishment (Fuchs et al., 2005; Hamlin et al., 2008; Pelloux et al., 2017). More importantly, we found that muscimol-baclofen BLA inactivation increased context-induced relapse to cocaine seeking in Context A after punishment-induced suppression of drug seeking in Context B; BLA inactivation also increased lever responding in Context B (Fig. $1 J)$. In contrast, BLA inactivation decreased context-induced relapse to cocaine seeking after extinction-induced suppression of cocaine seeking (Fig. $1 K$ ), confirming earlier results of Fuchs et al. (2005).

The mixed ANOVA of active lever presses during the $60 \mathrm{~min}$ relapse tests included the between-subject factor of Abstinence condition (punishment, extinction), and the within-subjects factors of Context (A, B) and Muscimol-baclofen dose $(0,50+50$ $\mathrm{ng} / \mathrm{side})$. This analysis showed significant effects of Context $\left(F_{(1,21)}=35.4 ; p=0.001\right)$, Abstinence condition $\times$ Muscimolbaclofen dose $\left(F_{(1,21)}=11.8, p=0.002\right)$, and more importantly, a significant interaction between the three factors $\left(F_{(1,21)}=5.7\right.$; $p=0.02)$. The triple interaction effect is because muscimolbaclofen injections increased lever presses in both Contexts A and $\mathrm{B}$ after punishment, but selectively decreased lever presses in Context A but not Context B after extinction.

Subsequent follow-up repeated-measures ANOVA of the Punishment group, which included the within-subjects factors of
Context and Muscimol-baclofen dose, showed main effects of Context $\left(F_{(1,10)}=27.9 ; p=0.001\right)$ and Muscimol-baclofen dose $\left(F_{(1,10)}=8.0 ; p=0.02\right)$ but no interaction between the two factors. The lack of significant interaction is because muscimolbaclofen injections increased lever responding in both Contexts $\mathrm{A}$ and $\mathrm{B}$. The same analysis of the Extinction group showed a significant main effect of Context $\left(F_{(1,11)}=18.6 ; p=0.001\right)$ but not Muscimol-baclofen dose $\left(F_{(1,11)}=4.4 ; p=0.06\right)$, and a significant interaction between the two factors $\left(F_{(1,11)}=4.6 ; p=\right.$ $0.05)$. The significant interaction is because muscimol-baclofen inactivation significantly decreased active lever presses in Context A, but not Context B.

Finally, we also examined the relapse test data of 10 excluded rats from the first run with cannula placements either within 0.8 $\mathrm{mm}$ dorsal to BLA (a posterior region of the caudate-putamen; $n=4$ ) or unilateral placement in this area combined with unilateral placement in BLA $(n=6)$. In these rats, muscimol-baclofen injections potentiated context-induced relapse in Context A (mean \pm SEM; $22 \pm 4$ and $50 \pm 9$ for the vehicle and muscimolbalcofen conditions, respectively; $p<0.05$ ) and provoked relapse in Context B (mean \pm SEM; $2 \pm 1$ and $27 \pm$ 9, respectively; $p<$ 0.05). We discuss these data and their implications for interpreting the bilateral BLA inactivation data (Fig. 1) in the Discussion.

\section{Effect of CeA inactivation on context-induced relapse after punishment versus extinction (Experiment 2)}

As in Experiment 1, we found selective context-induced relapse to cocaine seeking in Context A after suppression of responding in Context B in both the Punishment and Extinction groups (Fig. $2 J$, K; vehicle conditions). We also found that muscimol-baclofen $\mathrm{CeA}$ inactivation selectively decreased context-induced relapse to cocaine seeking in Context A after extinction-induced suppression of cocaine seeking in Context B (Fig. $2 K$ ). In contrast, CeA inactivation increased cocaine seeking in Context $\mathrm{B}$ after punishment-induced suppression but had no effect on contextinduced relapse in Context A (Figs. 2J). The mixed ANOVA of active lever presses during the 60 min relapse tests included the between-subjects factor of Abstinence condition (punishment, extinction), and the within-subjects factors of Context (A, B) and Muscimol-baclofen dose $(0,50+50 \mathrm{ng} /$ side $)$. This analysis showed a significant main effect of Context $\left(F_{(1,28)}=17.9 ; p<\right.$ $0.001)$ and significant interactions of Muscimol-baclofen dose $X$ Context $\left(F_{(1,28)}=9.36 ; p=0.01\right)$ and Muscimol-baclofen dose $\times$ Abstinence condition $\left(F_{(1,28)}=7.19 ; p=0.01\right)$.

Subsequent follow-up repeated-measures ANOVA of the Punishment group, which included the within-subjects factors of Context and Muscimol-baclofen dose, results in the following statistical results: main effect of Muscimol-baclofen dose $\left(F_{(1,15)}=\right.$ $4.1 ; p=0.06)$, main effect of Context $\left(F_{(1,15)}=3.84 ; p=0.07\right)$, and Context $\times$ Muscimol-baclofen dose $\left(F_{(1,15)}=3.1 ; p=0.1\right)$. The marginally significant effects of Context and Muscimolbaclofen doses are due to the selective increase in lever presses after CeA muscimol-baclofen injections before testing in Context $\mathrm{B}$ but not Context A. This observation was statistically confirmed by subsequent Fisher PLSD post hoc analyses showing significant differences between vehicle versus muscimol-baclofen in Context B $(p=0.01)$ but not in Context A $(p>0.1)$, and a significant difference between Context B versus Context A in the vehicle condition $(p=0.009)$ but not the muscimol-baclofen condition $(p>0.1)$.

The repeated-measures ANOVA of the Extinction group showed significant main effects of Context $\left(F_{(1,13)}=31.9 ; p<\right.$ $0.001)$ and Muscimol-baclofen dose $\left(F_{(1,13)}=7.6 ; p=0.02\right)$, and 
A Experimental timeline
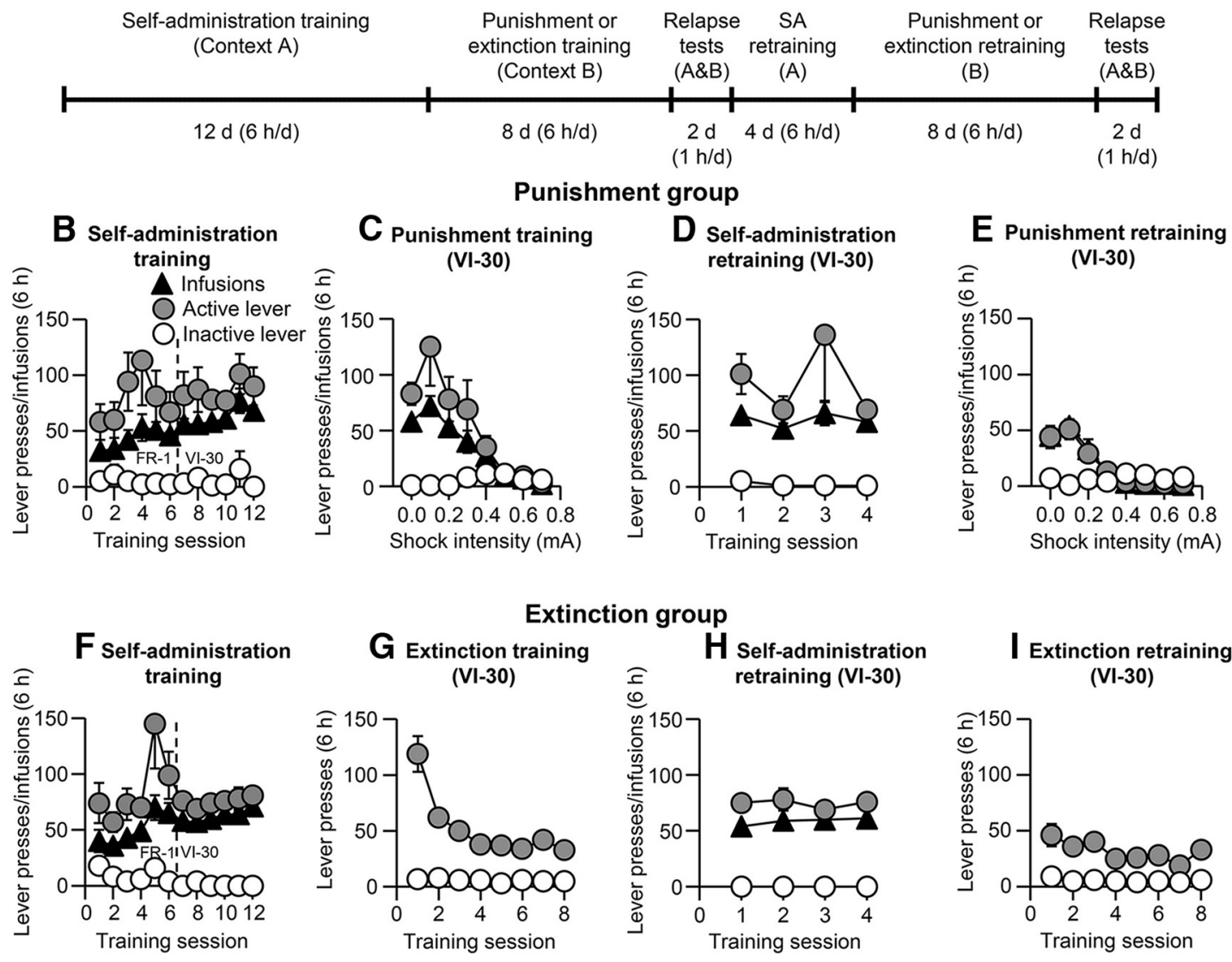

$\checkmark$ Punishment: relapse test

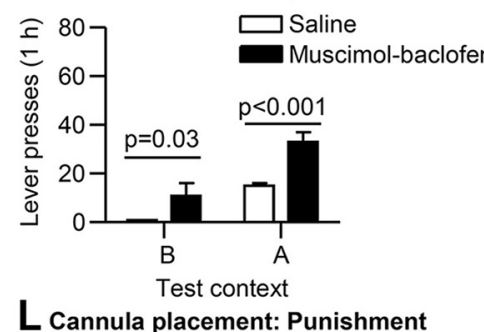

\section{K Extinction: relapse test}

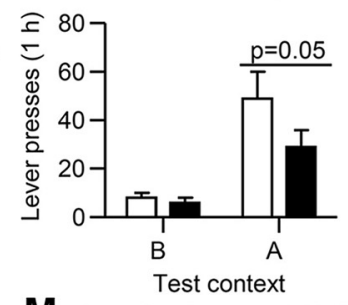

M Cannula placement: Extinction
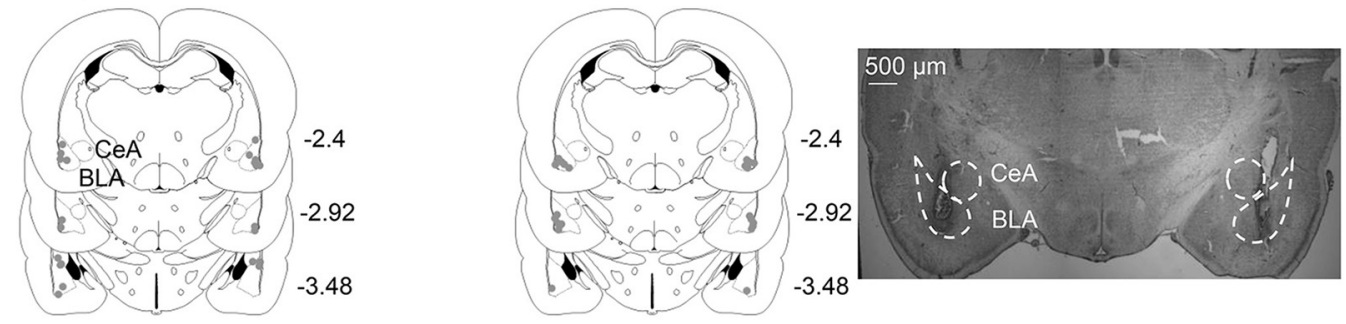

Figure 1. Opposite effects of BLA inactivation on context-induced relapse to cocaine seeking after suppression of drug self-administration by extinction versus punishment. $A$, Experimental timeline. $B$, Self-administration training, Punishment group: number of cocaine infusions $(0.75 \mathrm{mg} / \mathrm{kg} /$ infusion $)$ and lever presses during self-administration training in Context $A(n=11)$. The reinforcement schedules were FR-1 20 s timeout (days 1-6) and VI-30 (days 7-12). C, Punishment training: number of cocaine infusions and lever presses (VI-30) in Context B, with shock intensity increasing from 0.0 to $0.7 \mathrm{~mA}$ by $0.1 \mathrm{~mA}$ each day. D, Self-administration retraining, Punishment group: number of cocaine infusions and lever presses (VI-30) during the retraining phase in Context A. $\boldsymbol{E}$, Punishment retraining: number of cocaine infusions and lever presses (VI-30) in Context B. $\boldsymbol{F}$, Self-administration training Extinction group: number of cocaine infusions and lever presses during self-administration training in Context A $(n=12)$. The reinforcement schedules were FR-1 20 s timeout (days 1-6) and VI-30 (days 7-12). G, Extinction training: number of lever presses (VI-30) in Context B. H, Self-administration retraining, Extinction group: number of cocaine infusions and lever presses (VI-30) during the retraining phase in Context A. I, Extinction retraining: number of lever presses (VI-30) in Context B.J, Relapse test, Punishment group: number of lever presses on the previously active lever during the $1 \mathrm{~h}$ extinction sessions in Context B (Punishment) and Context A (Cocaine) after vehicle or muscimol-baclofen $(50+50 \mathrm{ng} / 0.5 \mu \mathrm{l} / \mathrm{side})$ into BLA. Lever presses led to contingent presentations of the compound tone-light cue previously paired with cocaine infusions during training, but not cocaine. $\boldsymbol{K}$, Relapse test, Extinction group: number of lever presses on the previously active lever during the $1 \mathrm{~h}$ extinction sessions in Contexts B (Extinction) and A (Cocaine). Lever presses led to contingent presentations of the compound tone-light cue previously paired with cocaine infusions during training, but not cocaine. All data are mean \pm SEM. $L$, $M$, Cannula placement: schematic representations of the cannula tip in BLA on standardized sections of the rat brain for the punishment $(\boldsymbol{L})$ and the extinction groups $(\boldsymbol{M})$. The numbers adjoining each section refer to distances from bregma (adapted from Paxinos and Watson, 2008). We added a representative photomicrograph of the cannula placement in the BLA. Scale bar, $500 \mu \mathrm{m}$. 
A Experimental timeline

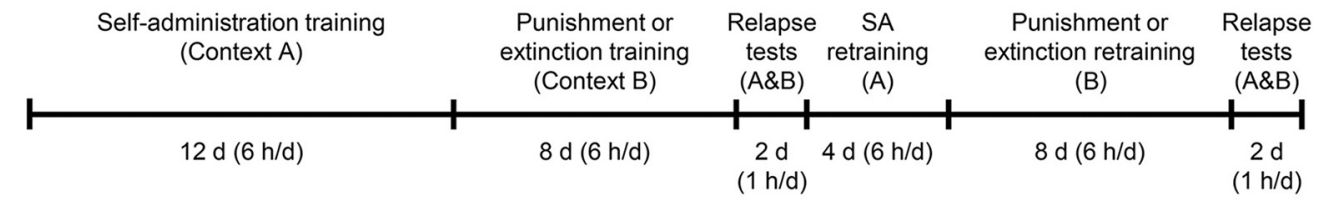

Punishment group
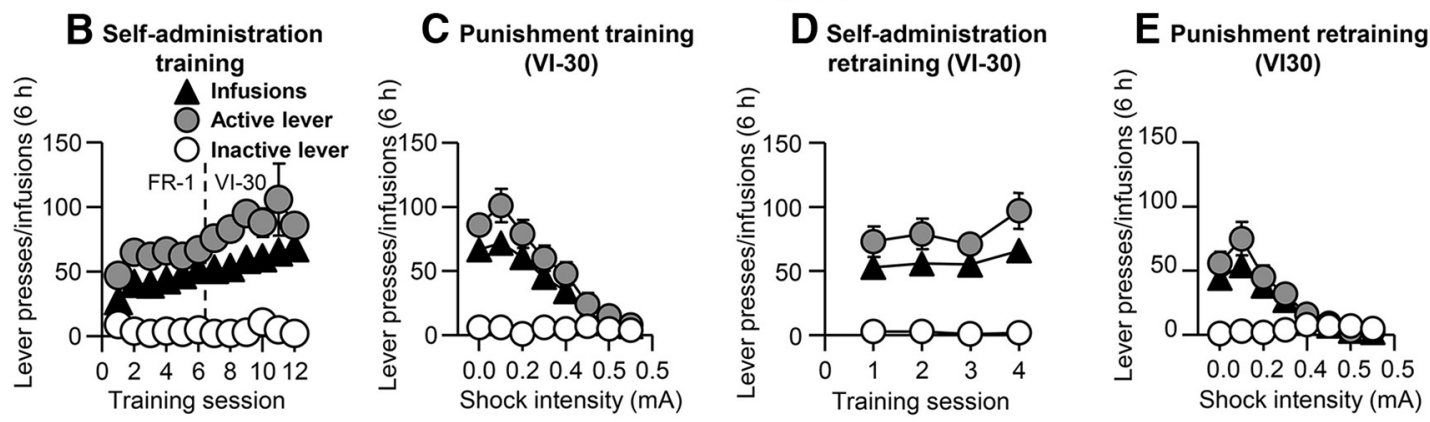

\section{Extinction group}
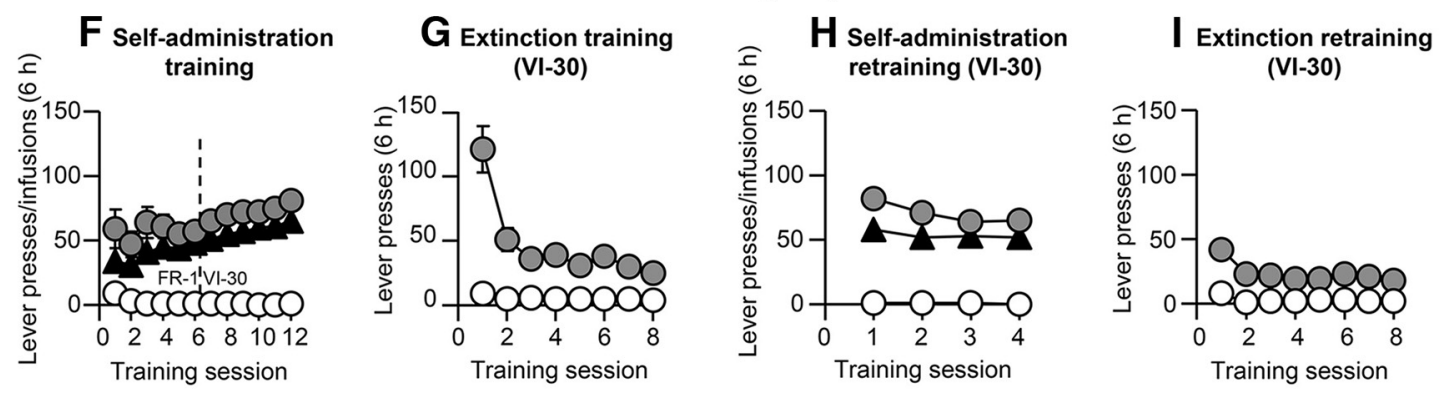

\section{J Punishment: relapse test}

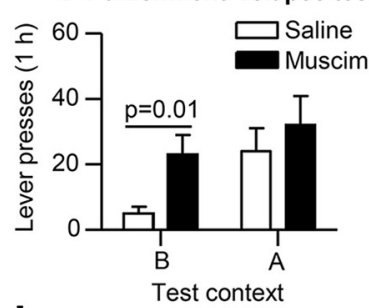

L Punishment: Cannula placement
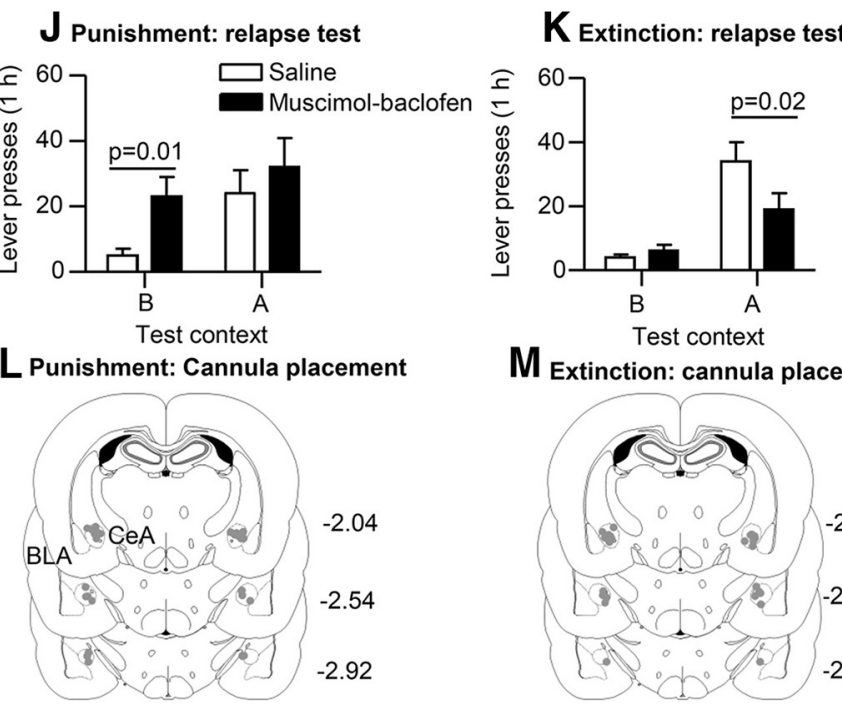

M Extinction: cannula placement

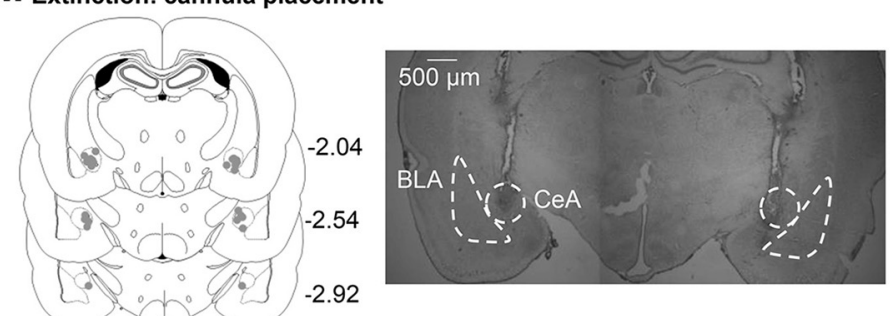

Figure 2. Different effects of CeA inactivation on context-induced relapse to cocaine seeking after suppression of drug self-administration by extinction versus punishment. $A$, Experimental timeline. $\boldsymbol{B}$, Self-administration training, Punishment group: number of cocaine infusions $(0.75 \mathrm{mg} / \mathrm{kg} /$ infusion $)$ and lever presses during self-administration training in Context $A(n=16)$. The reinforcement schedules were FR-1 20 s timeout (days 1-6) and VI-30 (days 7-12). C, Punishment training: number of cocaine infusions and lever presses (VI-30) in Context B, with shock intensity increasing from 0.0 to $0.5 \mathrm{~mA}$ by $0.1 \mathrm{~mA}$ each day. D, Self-administration retraining, Punishment group: number of cocaine infusions and lever presses (VI-30) during the retraining phase in Context A. $\boldsymbol{E}$, Punishment retraining: number of cocaine infusions and lever presses (VI-30) in Context B. $F$, Self-administration training, Extinction group: number of cocaine infusions and lever presses during self-administration training in Context A $(n=14)$. The reinforcement schedules were FR-1 20 s timeout (days 1-6) and VI-30 (days 7-12). G, Extinction training: number of lever presses (VI-30) in Context B. $\boldsymbol{H}$, Self-administration retraining, Extinction group: number of cocaine infusions and lever presses (VI-30) during the retraining phase in Context A. $I$, Extinction retraining: number of lever presses (VI-30) in Context B.J, Relapse test, Punishment group: number of lever presses on the previously active lever during the $1 \mathrm{~h}$ extinction sessions in Context B (Punishment) and Context A (Cocaine) after vehicle or muscimol-baclofen $(50+50 \mathrm{ng} / 0.5 \mu \mathrm{l} / \mathrm{side})$ into CeA. Lever presses led to contingent presentations of the compound tone-light cue previously paired with cocaine infusions during training, but not cocaine. $\boldsymbol{K}$, Relapse test, Extinction: number of lever presses on the previously active lever during the $1 \mathrm{~h}$ extinction sessions in Contexts B (Extinction) and A (Cocaine). Lever presses led to contingent presentations of the compound tone-light cue previously paired with cocaine infusions during training, but not cocaine. All data are mean \pm SEM. $\boldsymbol{L}, \boldsymbol{M}$, Cannula placement: schematic representations of the cannula tip in CeA on standardized sections of the rat brain for the punishment $(\boldsymbol{L})$ and the extinction groups $(\boldsymbol{M})$. The numbers adjoining each section refer to distances from bregma (adapted from Paxinos and Watson, 2008). We added a representative photomicrograph of the cannula placement in the BLA. Scale bar, $500 \mu \mathrm{m}$. 
a significant interaction between the two factors $\left(F_{(1,13)}=6.3\right.$; $p=0.03)$. The significant interaction is because muscimolbaclofen inactivation significantly decreased active lever presses in Context A but not Context B.

\section{Discussion}

We report three main findings. First, reversible inactivation of either BLA or CeA decreased context-induced relapse (reinstatement) to cocaine seeking in Context A after extinction in Context B. The BLA results confirm previous findings (Fuchs et al., 2005; Chaudhri et al., 2013), whereas the CeA results provide new evidence on the role of this amygdala subnucleus in context-induced reinstatement or renewal of drug seeking. Second, inactivation of BLA, but not CeA, increased context-induced relapse in Context A after punishment in Context B. Third, inactivation of BLA or CeA provoked relapse in Context B after punishment but not extinction. These results indicate that the role of amygdala in context-induced relapse depends on the method used to achieve abstinence. We discuss these findings below.

\section{Role of BLA on context-induced relapse of cocaine seeking after extinction versus punishment}

The main finding in our study is that BLA inactivation had opposite effects on context-induced relapse to cocaine seeking after extinction versus punishment. These findings are surprising in light of a large literature on the inhibitory effect of BLA inactivation or receptor blockade on conditioned drug effects in different animal models (Everitt and Robbins, 2000, 2005), including context- and cue-induced reinstatement of drug seeking (See, 2005; Lasseter et al., 2010; Bossert et al., 2013). The dissociable effects of BLA inactivation in the present study are also surprising, because context-induced reinstatement of cocaine seeking after either extinction (Hamlin et al., 2008) or punishment (Pelloux et al., 2017) is associated with increased BLA activity, as assessed by the neuronal activity marker Fos (Morgan and Curran, 1991; Cruz et al., 2013). What might account for the similar effect of context-induced BLA activation (Fos induction) after extinction or punishment versus the opposite effect of muscimolbaclofen inhibition of neuronal activity in BLA on contextinduced relapse? We speculate that this dissociation occurred because different BLA neuronal ensembles are activated during a test for context-induced relapse after extinction versus punishment. After extinction in Context B, BLA inactivation likely inhibits the relapse-associated ensembles in Context A that promote drug seeking. These ensembles may encode either traditional excitatory Pavlovian conditioned stimulus properties of Context A or occasion setter properties of this context; these learned associations are largely unaffected by extinction training in Context B (Crombag et al., 2008; Bouton et al., 2012; Khoo et al., 2017). After punishment in Context B, BLA inactivation likely will inhibit the same relapse-associated activated neurons in Context A. However, BLA inactivation will also inhibit distinct punishment-encoding ensembles that suppress drug seeking in both contexts (A and B). We propose that the predominant effect of muscimol-baclofen inactivation in the punishment group was to inhibit the context-independent punishment-encoding neurons, resulting in potentiation of context-induced relapse of cocaine seeking in Context A and relapse in Context B.

Our idea is supported by results from several studies showing that BLA inactivation increases punishment-suppressed cocaine- or food-reinforced operant responding (Pelloux et al., 2013; JeanRichard-Dit-Bressel and McNally, 2015; Orsini et al., 2015a,b; Piantadosi et al., 2017). Additionally, the notion that different BLA ensembles can encode both appetitive and aversive learned behaviors is supported by results from studies using tasks that assess risk-related behaviors where magnitude and probability of reward delivery versus omission and punishment versus safety conditions are experimentally manipulated (Orsini et al., 2015a; Winstanley and Floresco, 2016; Piantadosi et al., 2017), and from in vivo electrophysiology studies that include block trials of positive and negative outcomes in the same test session (Schoenbaum et al., 1998).

\section{Role of CeA on context-induced relapse of cocaine seeking after extinction versus punishment}

As with BLA inactivation, we found that CeA inactivation had different effects on context-induced relapse after extinction versus punishment: inhibition of context-induced relapse in Context A after extinction but not punishment, and relapse in Context $\mathrm{B}$ after punishment but not extinction. The findings on the role of $\mathrm{CeA}$ in context-induced relapse (reinstatement) to cocaine seeking after extinction extend results from previous studies using the reinstatement model on the role of this brain area in cue- and drug priming-induced reinstatement of cocaine seeking (Kruzich and See, 2001; Alleweireldt et al., 2006). The data also extend results from previous studies on CeA role in incubation of cocaine craving (Lu et al., 2005, 2007) and relapse to methamphetamine seeking after voluntary abstinence (Venniro et al., 2017b). More generally, the present and previous results implicating the CeA in relapse support the notion that the CeA plays a critical role in the incentive motivational effects of drug and non-drug rewards (Mahler and Berridge, 2012; Robinson et al., 2014; Warlow et al., 2017).

Like BLA inactivation, CeA inactivation increased lever presses in Context B after punishment-imposed abstinence in this context. However, these results should be interpreted with caution, because although the post hoc statistical comparison between saline versus muscimol-baclofen injections before the relapse test in Context B was significant $(p=0.01)$, the interaction between muscimol-baclofen dose and Context did not reach statistical significance in the overall repeated-measures ANOVA $(p=0.1)$. Of note, our findings on the relapse promoting effects of CeA inactivation in Context $\mathrm{B}$ extend results from previous studies on the role of $\mathrm{CeA}$ in punishment-induced suppression of operant responding for cocaine (Xue et al., 2012) or food (Margules, 1968; Shibata et al., 1986; Kataoka et al., 1987) in rats, and on punishment-induced suppression of operant responding for food in monkeys (Rygula et al., 2015).

Finally, the observation that CeA inactivation did not mimic the potentiation effect of BLA inactivation on context-induced relapse after punishment supports the notion that the two amygdala nuclei can play dissociable roles in controlling aversive and appetitive learned behaviors (Everitt and Robbins, 2005). For example, inhibition of CeA but not BLA activity decreases incubation of cocaine (Lu et al., 2005) or methamphetamine (Li et al., 2015) craving, and optogenetic activation of CeA but not BLA enhances the motivation to seek cocaine or food (Robinson et al., 2014; Warlow et al., 2017).

\section{Methodological considerations}

One issue is that the effect of muscimol-baclofen on relapse was due to nonspecific effects on operant responding during testing. This possibility is very unlikely because muscimol-baclofen inactivation of BLA and CeA increased active lever presses in the punishment groups and decreased responding in the extinction groups. Additionally, during the relapse tests, BLA and CeA 
inactivation had no effect on inactive lever presses, a putative measure of nonselective motor suppression or activation and response generalization (Shalev et al., 2002).

Another issue is the anatomical specificity of the muscimolbaclofen injections into BLA and CeA. This is a general issue in intracranial injection studies because after injections, drugs diffuse away from the target injection site and can affect neuronal activity in adjacent brain areas (Wise and Hoffman, 1992). In our study, we found that after punishment-induced suppression of cocaine seeking, muscimol-baclofen injections provoked relapse in anatomically excluded rats with cannulas located within 0.8 $\mathrm{mm}$ dorsal to BLA (posterior caudate-putamen area) or unilateral placement in this region plus unilateral placement in BLA. Based on the previous literature on the BLA's role in punishment (Pelloux et al., 2013; Jean-Richard-Dit-Bressel and McNally, 2015), we suspect that the behavioral effects in the excluded rats are mediated by muscimol-baclofen diffusion into BLA or by unilateral BLA inactivation. However, in the absence of additional studies selectively targeting the posterior caudate-putamen with more dorsal placements, we cannot rule out a potential role of this region in context-induced relapse after punishment.

\section{Conclusions and implications for animal models of drug relapse}

As mentioned in the introduction, the main question that inspired our studies on context-induced relapse after punishmentimposed abstinence (Marchant et al., 2013b) is whether similar or different mechanisms mediate context-induced relapse after extinction-induced suppression of drug seeking in the absence of the drug versus punishment-induced suppression of drug seeking in the presence of the drug. Results from previous studies suggested an overlap between brain regions and circuits controlling context-induced relapse after extinction versus punishment (Marchant et al., 2015; Khoo et al., 2017). However, this conclusion was based on historical comparisons of studies performed under different experimental conditions. In the present study, we directly compared context-induced relapse to cocaine seeking after extinction or punishment under the same experimental conditions and found that BLA and CeA inactivation decreased context-induced relapse after extinction, whereas BLA but not CeA inactivation increased context-induced relapse after punishment. Thus, together with the results from the previous studies (Marchant et al., 2015; Khoo et al., 2017), it appears that the brain circuits controlling context-induced relapse after extinction versus punishment only partially overlap.

Finally, the finding that the role of amygdala's activity in relapse depends on the method used to achieve abstinence has implications for both animal models of relapse and human relapse. Regarding animal models, our study highlights the importance of studying relapse under abstinence conditions that more closely mimic the human condition (Marchant et al., 2013a; Venniro et al., 2016). Regarding clinical implications, our study suggests that the role of human amygdala in drug relapse can be dependent on the external environmental conditions and the internal motivational factors that led to abstinence in individual drug addicts.

\section{References}

Adhikary S, Caprioli D, Venniro M, Kallenberger P, Shaham Y, Bossert JM (2017) Incubation of extinction responding and cue-induced reinstatement, but not context- or drug priming-induced reinstatement, after withdrawal from methamphetamine. Addict Biol 22:977-990. CrossRef Medline

Ahmed SH, Koob GF (1998) Transition from moderate to excessive drug intake: change in hedonic set point. Science 282:298-300. CrossRef Medline
Alleweireldt AT, Hobbs RJ, Taylor AR, Neisewander JL (2006) Effects of SCH-23390 infused into the amygdala or adjacent cortex and basal ganglia on cocaine seeking and self-administration in rats. Neuropsychopharmacology 31:363-374. CrossRef Medline

Bossert JM, Liu SY, Lu L, Shaham Y (2004) A role of ventral tegmental area glutamate in contextual cue-induced relapse to heroin seeking. J Neurosci 24:10726-10730. CrossRef Medline

Bossert JM, Marchant NJ, Calu DJ, Shaham Y (2013) The reinstatement model of drug relapse: recent neurobiological findings, emerging research topics, and translational research. Psychopharmacology (Berl) 229:453476. CrossRef Medline

Bossert JM, Adhikary S, St Laurent R, Marchant NJ, Wang HL, Morales M, Shaham Y (2016) Role of projections from ventral subiculum to nucleus accumbens shell in context-induced reinstatement of heroin seeking in rats. Psychopharmacology 233:1991-2004. CrossRef Medline

Bouton ME, Bolles RC (1979) Contextual control of the extinction of conditioned fear. Learn Motiv 10:445-466. CrossRef

Bouton ME, Winterbauer NE, Todd TP (2012) Relapse processes after the extinction of instrumental learning: renewal, resurgence, and reacquisition. Behav Processes 90:130-141. CrossRef Medline

Caprioli D, Venniro M, Zhang M, Bossert JM, Warren BL, Hope BT, Shaham Y (2017) Role of dorsomedial striatum neuronal ensembles in incubation of methamphetamine craving after voluntary abstinence. J Neurosci 37:1014-1027. CrossRef Medline

Chaudhri N, Woods CA, Sahuque LL, Gill TM, Janak PH (2013) Unilateral inactivation of the basolateral amygdala attenuates context-induced renewal of Pavlovian-conditioned alcohol-seeking. Eur J Neurosci 38:27512761. CrossRef Medline

Crombag HS, Bossert JM, Koya E, Shaham Y (2008) Review. Contextinduced relapse to drug seeking: a review. Philos Trans R Soc Lond B Biol Sci 363:3233-3243. CrossRef Medline

Cruz FC, Koya E, Guez-Barber DH, Bossert JM, Lupica CR, Shaham Y, Hope BT (2013) New technologies for examining the role of neuronal ensembles in drug addiction and fear. Nat Rev Neurosci 14:743-754. CrossRef Medline

Epstein DH, Preston KL, Stewart J, Shaham Y (2006) Toward a model of drug relapse: an assessment of the validity of the reinstatement procedure. Psychopharmacology (Berl) 189:1-16. CrossRef Medline

Everitt BJ, Robbins TW (2000) Second-order schedules of drug reinforcement in rats and monkeys: measurement of reinforcing efficacy and drugseeking behaviour. Psychopharmacology 153:17-30. CrossRef Medline

Everitt BJ, Robbins TW (2005) Neural systems of reinforcement for drug addiction: from actions to habits to compulsion. Nat Neurosci 8:14811489. CrossRef Medline

Fuchs RA, Evans KA, Ledford CC, Parker MP, Case JM, Mehta RH, See RE (2005) The role of the dorsomedial prefrontal cortex, basolateral amygdala, and dorsal hippocampus in contextual reinstatement of cocaine seeking in rats. Neuropsychopharmacology 30:296-309. CrossRef Medline

Funk D, Coen K, Tamadon S, Hope BT, Shaham Y, Lê AD (2016) Role of central amygdala neuronal ensembles in incubation of nicotine craving. J Neurosci 36:8612-8623. CrossRef Medline

Hamlin AS, Clemens KJ, McNally GP (2008) Renewal of extinguished cocaine-seeking. Neuroscience 151:659-670. CrossRef Medline

Jean-Richard-Dit-Bressel P, McNally GP (2015) The role of the basolateral amygdala in punishment. Learn Mem 22:128-137. CrossRef Medline

Kataoka Y, Shibata K, Yamashita K, Ueki S (1987) Differential mechanisms involved in the anticonflict action of benzodiazepines injected into the central amygdala and mammillary body. Brain Res 416:243-247. CrossRef Medline

Katz JL, Higgins ST (2003) The validity of the reinstatement model of craving and relapse to drug use. Psychopharmacology 168:21-30. CrossRef Medline

Khoo SY, Gibson GD, Prasad AA, McNally GP (2017) How contexts promote and prevent relapse to drug seeking. Genes Brain Behav 16:185-204. CrossRef Medline

Kruzich PJ, See RE (2001) Differential contributions of the basolateral and central amygdala in the acquisition and expression of conditioned relapse to cocaine-seeking behavior. J Neurosci 21:RC155. Medline

Lasseter HC, Xie X, Ramirez DR, Fuchs RA (2010) Prefrontal cortical regulation of drug seeking in animal models of drug relapse. Curr Top Behav Neurosci 3:101-117. CrossRef Medline

Li X, Zeric T, Kambhampati S, Bossert JM, Shaham Y (2015) The central 
amygdala nucleus is critical for incubation of methamphetamine craving. Neuropsychopharmacology 40:1297-1306. CrossRef Medline

Lu L, Hope BT, Dempsey J, Liu SY, Bossert JM, Shaham Y (2005) Central amygdala ERK signaling pathway is critical to incubation of cocaine craving. Nat Neurosci 8:212-219. CrossRef Medline

Lu L, Uejima JL, Gray SM, Bossert JM, Shaham Y (2007) Systemic and central amygdala injections of the $\mathrm{mGluR}_{2 / 3}$ agonist LY379268 attenuate the expression of incubation of cocaine craving. Biol Psychiatry 61:591-598. CrossRef Medline

Mahler SV, Berridge KC (2012) What and when to "want"? Amygdalabased focusing of incentive salience upon sugar and sex. Psychopharmacology (Berl) 221:407-426. CrossRef Medline

Marchant NJ, Kaganovsky K (2015) A critical role of nucleus accumbens dopamine D1-family receptors in renewal of alcohol seeking after punishment-imposed abstinence. Behav Neurosci 129:281-291. CrossRef Medline

Marchant NJ, Li X, Shaham Y (2013a) Recent developments in animal models of drug relapse. Curr Opin Neurobiol 23:675-683. CrossRef Medline

Marchant NJ, Khuc TN, Pickens CL, Bonci A, Shaham Y (2013b) Contextinduced relapse to alcohol seeking after punishment in a rat model. Biol Psychiatry 73:256-262. CrossRef Medline

Marchant NJ, Rabei R, Kaganovsky K, Caprioli D, Bossert JM, Bonci A, Shaham Y (2014) A critical role of lateral hypothalamus in context-induced relapse to alcohol seeking after punishment-imposed abstinence. J Neurosci 34:7447-7457. CrossRef Medline

Marchant NJ, Kaganovsky K, Shaham Y, Bossert JM (2015) Role of corticostriatal circuits in context-induced reinstatement of drug seeking. Brain Res 1628:219-232. CrossRef Medline

Marchant NJ, Campbell EJ, Whitaker LR, Harvey BK, Kaganovsky K, Adhikary S, Hope BT, Heins RC, Prisinzano TE, Vardy E, Bonci A, Bossert JM, Shaham Y (2016) Role of ventral subiculum in context-induced relapse to alcohol seeking after punishment-imposed abstinence. J Neurosci 36:3281-3294. CrossRef Medline

Margules DL (1968) Noradrenergic basis of inhibition between reward and punishment in amygdala. J Comp Physiol Psychol 66:329-334. CrossRef Medline

Marlatt GA (2002) Do animal models provide a valid analogue for human drug lapse and relapse? Comment on Leri and Stewart (2002). Exp Clin Psychopharmacol 10:359-360; discussion 364-356. CrossRef Medline

McFarland K, Kalivas PW (2001) The circuitry mediating cocaine-induced reinstatement of drug-seeking behavior. J Neurosci 21:8655-8663. Medline

Morgan JI, Curran T (1991) Stimulus-transcription coupling in the nervous system: involvement of the inducible proto-oncogenes fos and jun. Annu Rev Neurosci 14:421-451. CrossRef Medline

O’Brien CP, Childress AR, McLellan AT, Ehrman R (1992) Classical conditioning in drug-dependent humans. Ann N Y Acad Sci 654:400-415. CrossRef Medline

Orsini CA, Trotta RT, Bizon JL, Setlow B (2015a) Dissociable roles for the basolateral amygdala and orbitofrontal cortex in decision-making under risk of punishment. J Neurosci 35:1368-1379. CrossRef Medline

Orsini CA, Moorman DE, Young JW, Setlow B, Floresco SB (2015b) Neural mechanisms regulating different forms of risk-related decision-making: insights from animal models. Neurosci Biobehav Rev 58:147-167. CrossRef Medline

Paxinos G, Watson C (2008) The rat brain in stereotaxic coordinates, Ed 6. San Diego: Academic.

Pelloux Y, Murray JE, Everitt BJ (2013) Differential roles of the prefrontal cortical subregions and basolateral amygdala in compulsive cocaine seeking and relapse after voluntary abstinence in rats. Eur J Neurosci 38:30183026. CrossRef Medline

Pelloux Y, Hoots JK, Cifani C, Adhikary S, Martin J, Minier-Toribio A,
Bossert JM, Shaham Y (2017) Context-induced relapse to cocaine seeking after punishment-imposed abstinence is associated with activation of cortical and subcortical brain regions. Addict Biol. Advance online publication. doi: 10.1111/adb.12527. Medline

Piantadosi PT, Yeates DC, Wilkins M, Floresco SB (2017) Contributions of basolateral amygdala and nucleus accumbens subregions to mediating motivational conflict during punished reward-seeking. Neurobiol Learn Mem 140:92-105. CrossRef Medline

Robinson MJ, Warlow SM, Berridge KC (2014) Optogenetic excitation of central amygdala amplifies and narrows incentive motivation to pursue one reward above another. J Neurosci 34:16567-16580. CrossRef Medline

Rygula R, Clarke HF, Cardinal RN, Cockcroft GJ, Xia J, Dalley JW, Robbins TW, Roberts AC (2015) Role of central serotonin in anticipation of rewarding and punishing outcomes: effects of selective amygdala or orbitofrontal 5-HT depletion. Cereb Cortex 25:3064-3076. CrossRef Medline

Schoenbaum G, Chiba AA, Gallagher M (1998) Orbitofrontal cortex and basolateral amygdala encode expected outcomes during learning. Nat Neurosci 1:155-159. CrossRef Medline

See RE (2005) Neural substrates of cocaine-cue associations that trigger relapse. Eur J Pharmacol 526:140-146. CrossRef Medline

Shalev U, Grimm JW, Shaham Y (2002) Neurobiology of relapse to heroin and cocaine seeking: a review. Pharmacol Rev 54:1-42. CrossRef Medline

Shibata K, Kataoka Y, Yamashita K, Ueki S (1986) An important role of the central amygdaloid nucleus and mammillary body in the mediation of conflict behavior in rats. Brain Res 372:159-162. CrossRef Medline

Stopper CM, Floresco SB (2014) What's better for me? Fundamental role for lateral habenula in promoting subjective decision biases. Nat Neurosci 17:33-35. CrossRef Medline

Vanderschuren LJM, Minnaard AM, Smeets JAS, Lesscher HMB (2017) Punishment models of addictive behavior. Curr Opin Behav Sci 13:7784. CrossRef

Venniro M, Caprioli D, Shaham Y (2016) Animal models of drug relapse and craving: from drug priming-induced reinstatement to incubation of craving after voluntary abstinence. Prog Brain Res 224:25-52. CrossRef Medline

Venniro M, Zhang M, Shaham Y, Caprioli D (2017a) Incubation of methamphetamine but not heroin craving after voluntary abstinence in male and female rats. Neuropsychopharmacology 42:1126-1135. CrossRef Medline

Venniro M, Caprioli D, Zhang M, Whitaker LR, Zhang S, Warren BL, Cifani C, Marchant NJ, Yizhar O, Bossert JM, Chiamulera C, Morales M, Shaham Y (2017b) The anterior insular cortex $\rightarrow$ central amygdala glutamatergic pathway is critical to relapse after contingency management. Neuron 96:414427.e8. CrossRef Medline

Waldorf D, Reinarman C, Murphy C (1991) Cocaine changes: the processes of using and quitting cocaine, pp 5-27. Philadelphia: Temple UP.

Warlow SM, Robinson MJF, Berridge KC (2017) Optogenetic central amygdala stimulation intensifies and narrows motivation for cocaine. J Neurosci 37: 8330-8348. CrossRef Medline

Wikler A (1973) Dynamics of drug dependence: implications of a conditioning theory for research and treatment. Arch Gen Psychiatry 28:611616. CrossRef Medline

Winstanley CA, Floresco SB (2016) Deciphering decision making: variation in animal models of effort- and uncertainty-based choice reveals distinct neural circuitries underlying core cognitive processes. J Neurosci 36: 12069-12079. CrossRef Medline

Wise RA, Hoffman DC (1992) Localization of drug reward mechanisms by intracranial injections. Synapse 10:247-263. CrossRef Medline

Xue Y, Steketee JD, Sun W (2012) Inactivation of the central nucleus of the amygdala reduces the effect of punishment on cocaine self-administration in rats. Eur J Neurosci 35:775-783. CrossRef Medline 